\title{
Dynamics of growth and weight transitions in a pediatric cohort from India
}

\author{
Manu Raj ${ }^{* 1}$, Karimassery R Sundaram², Mary Paul ${ }^{1}$, Abish Sudhakar ${ }^{1}$ and \\ Raman K Kumar ${ }^{1}$
}

Address: ${ }^{1}$ Department of Pediatric Cardiology, Amrita Institute of Medical Sciences and Research Centre, Kochi, Kerala, India and ${ }^{2}$ Department of Biostatistics, Amrita Institute of Medical Sciences and Research Centre, Kochi, Kerala, India

Email: Manu Raj* - drmanuraj@gmail.com; Karimassery R Sundaram - krsundaram@aims.amrita.edu; Mary Paul - marypaulo@rediffmail.com; Abish Sudhakar - abishsudhakar08@gmail.com; Raman K Kumar - rkrishnakumar@aims.amrita.edu

* Corresponding author

Published: 23 November 2009

Nutrition Journal 2009, 8:55 doi:10.1/86//475-289/-8-55

This article is available from: http://www.nutritionj.com/content/8/l/55

(c) 2009 Raj et al; licensee BioMed Central Ltd.

This is an Open Access article distributed under the terms of the Creative Commons Attribution License (http://creativecommons.org/licenses/by/2.0), which permits unrestricted use, distribution, and reproduction in any medium, provided the original work is properly cited.
Received: 9 July 2009

Accepted: 23 November 2009

\begin{abstract}
Background: There is paucity of information regarding time trends of weight status in children from rapidly developing economies like India. The aim of the study was to analyse the dynamics of growth and weight transitions in a cohort of school children from India.
\end{abstract}

Methods: A population of 25228 children was selected using stratified random sampling method from schools in a contiguous area in Ernakulam District, Kerala, India. Weight and height were measured at two time points, one in 2003-04 and another in 2005-06. The paired data of $12 \quad 129$ children aged 5- 16 years were analysed for the study.

Results: The mean interval between the two surveys was $2.02 \pm 0.32$ years. The percentage of underweight, normal weight, overweight and obese children in the year 2003-04 were 38.4\%, $56.6 \%, 3.7 \%$, and I.3\% respectively. The corresponding figures in year $2005-06$ were $29.9 \%, 63.6 \%$, $4.8 \%$ and $1.7 \%$ respectively. Among the underweight children, $34.8 \%$ migrated to normal weight status and $0.1 \%$ migrated to overweight status. Conversion of underweight to normal weight predominated in urban area and girls. Among the normal weight children, $8.6 \%$ migrated to underweight, $4.1 \%$ migrated to overweight and $0.4 \%$ migrated to obesity. Conversion of normal weight to overweight status predominated in urban area, private schools and boys. Conversion of normal weight to underweight predominated in rural area, government schools and boys. Among the overweight children, $26.7 \%$ migrated to normal weight status, $16.4 \%$ became obese and $56.9 \%$ retained their overweight status. Of the obese children, $6.2 \%$ improved to normal weight status, $25.3 \%$ improved to overweight status and $68.5 \%$ remained as obese in 2005-06. There was significant difference in trends between socio demographic subgroups regarding conversion of underweight status to normal weight as well as normal weight status to overweight.

Conclusion: The study population is experiencing rapid growth and nutritional transitions characterised by a decline in the underweight population coupled with an escalation of the overweight population. The heterogeneous nature of this transition appears to be due to differences in socio demographic factors. 


\section{Background}

Globally, countries are passing through concurrent epidemiological, demographic and nutritional transitions [1]. The term nutritional transition is used to characterize the shift in disease patterns towards nutrition related non communicable diseases. This shift in disease patterns is associated with changes in behaviour, lifestyles, diets, physical activity, smoking and alcohol consumption [2]. The rapidity of such nutritional transitions is clearly visible in emerging nations from Asia. Countries like India, China, Thailand, Indonesia and South Korea are currently witnessing such transitions [3-7]. There is evidence of such a rapid nutritional transition amplifying the burden of chronic diseases and obesity in India [3]. Economic reforms have modified pediatric growth patterns as well as prevalence of under nutrition and overweight in large economies like China [4]. Time trends in childhood obesity reported from India predicts an escalating burden of obesity related issues in the near future $[8,9]$. In spite of these rapid changes, many countries have significant levels of malnutrition and child mortality together with rising prevalence of obesity and non communicable diseases [1]. This double burden is a result of an interaction between various factors of which social inequality merits more attention than others. Social inequality has emerged as a major factor in differential mortality in both developed and developing countries [1].

The relationship between socioeconomic levels and weight status shows interesting asymmetry [10]. The urban poor of developed economies are particularly vulnerable to childhood obesity in contrast to developing nations where the urban rich are extremely at risk for the same [11]. While the former group appears vulnerable due to poor diet and decreasing physical activity, the latter remains at risk probably due to an increased affinity towards a western type of lifestyle [12-15]. A recent systematic review demonstrated that associations between physical environmental variables and obesity differ by gender, age, socio economic status and population density [16]. Cohort studies have demonstrated that social patterning of overweight varies between and within populations over time [17]. National surveys from China have demonstrated the rapidity of overweight progression as well as the differential growth of overweight in terms of varying levels of urbanization [18]. In Thailand, the prevalence of overweight and obesity among children and adolescents increased dramatically during the last two decades [5]. This was more pronounced in children from private schools and urban communities than in those from public schools or rural communities. Studies from India have also stressed the role of socio economic status and urbanization in promoting childhood obesity $[8,19]$. The aim of this study was to examine the dynamics of growth and weight transitions in school children from a selected population in India and to assess the influence of socio demographic factors in modifying these transitions.

\section{Methods}

A contiguous area with a population of approximately 1.37 million was selected from Ernakulam district, in central Kerala, South India. Sampling was done by stratified random sampling method. Schools in the area were stratified into 5 groups according to the number of students and a representative sample of 46 schools with a cumulative population of 25228 children was randomly chosen. Anthropometric measurements, which consisted of height and weight were recorded for 24842 children of age group 5-16 years in 2003-04. The same set of measurements was repeated in the selected schools in 2005-06 covering a total of 20263 . The anthropometric measurements were recorded by personnel specifically trained for the study. One trained person was dedicated for recording weight and another for height, to avoid inter observer error. Intra observer error was within acceptable limits for both height and weight measurements as documented by the co-efficient of reliability $(\mathrm{R}>0.99)$. Height was measured to the nearest 0.5 centimeter by a wall-mounted stadiometer. Weight was measured to the nearest 0.5 kilogram by a mechanical weighing scale. Both equipments were standardized at regular intervals. A total of 12 129 children had two sets of measurements, one in 200304 and other in 2005-06. Paired data of these children were used for studying dynamics of growth and weight trends in the study population. Children with Body Mass Index (BMI) less than or equal to $5^{\text {th }}$ percentile of reference data were considered underweight. Children with BMI more than or equal to $85^{\text {th }}$ and less than $95^{\text {th }}$ percentile of reference data were considered overweight. Children having BMI more than or equal to $95^{\text {th }}$ percentile were considered obese [20]. The reference data used to identify the BMI cut offs as well as conversion of weight and height to Z scores were taken from CDC 2000 data set for growth parameters in children and adolescents [21]. Age in months was used for converting BMI, weight and height to $\mathrm{Z}$ scores as per CDC reference. The cohort was divided into various subgroups for detailed analysis. Schools were divided into government and private schools. Government schools receive subsidies from the educational department enabling them to provide education at less than INR 500 per year per student (approximately US\$12). Private schools receive no subsidies and charge students INR 5000 and above per year. Schools were also divided into rural and urban as well. Rural area was defined if more than 75 percent of adult male population was engaged in agricultural occupations along with lower levels of developmental indices. Non-rural areas were designated as urban areas. 


\section{Statistical analysis}

The data were analyzed using SPSS software version 15. Anthropometric transition was assessed by converting the corresponding parameters to $\mathrm{Z}$ scores and comparing their means. Paired samples test was used for comparing individual subgroup time transitions. Independent samples test was used for comparing time transitions of inter subgroup differences. Pearson Chi square test was used for comparing weight transitions among various sub groups. Significance was assigned for a P value $<0.05$.

\section{Ethical approval}

Approval for the study was obtained from the ethical committee of the home institution in compliance with the guidelines issued by Indian Council of Medical Research. Consent to conduct the survey on students was obtained from parents through school authorities, who arranged parent meetings in the respective schools. Verbal assent was taken from the children after demonstrating and explaining the procedure.

\section{Results}

Descriptive data of the cohort based on the two periods 2003-04 and 2005-06 is given in Table 1. Age and gender specific BMI percentiles of the cohort with respect to socio demographic subgroups are given in Table 2. The mean interval between the two surveys was $2.02 \pm 0.32$ years. The percentage of underweight, normal weight, overweight and obese children in the year 2003 were $38.4 \%$, $56.6 \%, 3.7 \%$, and $1.3 \%$ respectively. The corresponding figures when the cohort was examined two years later were $29.9 \%, 63.6 \%, 4.8 \%$ and $1.7 \%$ respectively. The difference in categories of weight status between 2003 and 2005 appears to be statistically significant $(P<0.0001)$.

Among the 4658 underweight children in 2003-04, $65.2 \%$ remained underweight and the rest migrated to other weight groups. Of the 6864 normal weight children in 2003-04, 86.9\% remained normal and the rest migrated to other weight groups. Among the 445 overweight children in 2003-04, 56.9\% retained their overweight status and the remaining migrated to other weight groups. Of the 162 obese children in 2003-04 68.5\% remained as obese and the rest migrated to other weight groups in 2005-06. No child who was overweight or obese in 2003-04 migrated to underweight status in 2005-06. Similarly, no child who was under weight in 2003-04 became obese in 2005-06 screening. The details of the weight transitions across various weight groups are presented in Table 3.

Table I: Descriptive data of the study cohort

\begin{tabular}{|c|c|c|c|c|c|c|c|c|}
\hline \multirow{2}{*}{$\begin{array}{l}2003 \\
\begin{array}{l}\text { Age } \\
\text { (yrs) }\end{array}\end{array}$} & \multicolumn{4}{|c|}{ Boys } & \multicolumn{4}{|c|}{ Girls } \\
\hline & $\mathbf{N}$ & $\begin{array}{l}\text { Height } \\
\text { (cm) }\end{array}$ & $\begin{array}{l}\text { Weight } \\
\text { (kg) }\end{array}$ & $\begin{array}{l}\text { BMI } \\
\left(\mathbf{k g} / \mathbf{m}^{2}\right)\end{array}$ & $\mathbf{N}$ & $\begin{array}{l}\text { Height } \\
\text { (cm) }\end{array}$ & $\begin{array}{l}\text { Weight } \\
\text { (kg) }\end{array}$ & $\begin{array}{l}\text { BMI } \\
\left(\mathrm{kg} / \mathrm{m}^{2}\right)\end{array}$ \\
\hline 5 & 293 & $109.7(4.6)$ & $16.7(2.2)$ & $13.8(1.3)$ & 223 & $108.6(5.5)$ & $16.3(2.4)$ & $13.8(1.5)$ \\
\hline 6 & 580 & II 5.5 (5.4) & 19.1 (3.2) & $14.2(1.6)$ & 486 & II $4.3(5.5)$ & $18.6(3.5)$ & $14.2(1.8)$ \\
\hline 7 & 574 & $120.7(6.2)$ & $21.1(4.1)$ & 14.4 (1.9) & 425 & $120.2(5.8)$ & $20.8(3.8)$ & 14.3 (I.8) \\
\hline 8 & 534 & $126.6(6.1)$ & $23.8(4.6)$ & I $4.8(2.0)$ & 421 & $125.5(6.4)$ & $23.4(5.3)$ & I4.7 (2.2) \\
\hline 9 & 720 & $131.9(6.5)$ & $26.4(6.0)$ & I5.I (2.3) & 737 & $131.4(6.5)$ & $26.4(5.6)$ & I5.I (2.3) \\
\hline 10 & 812 & $135.9(6.8)$ & $28.5(6.9)$ & I5.3 (2.6) & 946 & I 36.5 (7.1) & $28.8(6.2)$ & I5.3 (2.3) \\
\hline II & 733 & I 40.5 (7.4) & $3 \mid .2(7.5)$ & I5.6 (2.7) & 1059 & 142.3 (7.1) & $32.7(7.1)$ & $16.0(2.6)$ \\
\hline 12 & 842 & $145.9(7.4)$ & 33.9 (7.4) & $15.8(2.5)$ & 1122 & I $47.9(7.2)$ & $36.7(8.1)$ & $16.6(2.8)$ \\
\hline 13 & 556 & I 52.5 (8.7) & $39.2(9.8)$ & I $6.7(3.0)$ & 706 & $151.0(6.7)$ & $39.7(7.7)$ & I7.3 (2.7) \\
\hline 14 & 197 & I55.9 (8.7) & $4 I .6(9.7)$ & I $7.0(2.9)$ & 146 & $151.9(6.1)$ & $40.9(7.3)$ & I7.7 (2.7) \\
\hline \multicolumn{9}{|l|}{2005} \\
\hline 7 & 207 & I $22.4(5.1)$ & $21.3(3.8)$ & I4.I (I.8) & 163 & I22. I (5.7) & $21.6(5.1)$ & $14.4(2.4)$ \\
\hline 8 & 592 & I $27.4(5.8)$ & $24.5(5.2)$ & $15.0(2.3)$ & 489 & $126.1(6.3)$ & $23.7(4.9)$ & $14.8(2.1)$ \\
\hline 9 & 574 & $131.8(6.5)$ & $26.8(5.9)$ & I5.3 (2.4) & 454 & $131.7(6.6)$ & $26.6(5.7)$ & I5.2(2.3) \\
\hline 10 & 551 & I $37.5(6.8)$ & $30.1(6.8)$ & I5.8 (2.6) & 406 & I $38.0(7.2)$ & $30.6(7.4)$ & $15.9(2.7)$ \\
\hline II & 746 & I 42.5 (7.5) & $33.3(8.1)$ & $16.2(2.8)$ & 763 & I 43.7 (7.4) & $34.4(8.2)$ & $16.5(2.8)$ \\
\hline 12 & 837 & I 46.7 (8.0) & $35.9(9.2)$ & $16.5(3.0)$ & 989 & I 48.7 (6.6) & $38.4(8.3)$ & I7.2 (2.9) \\
\hline 13 & 754 & I 53.7 (8.7) & $40.7(9.4)$ & I7.I (2.9) & 1034 & I $52.0(6.0)$ & $41.4(7.5)$ & $17.9(2.8)$ \\
\hline 14 & 836 & $160.1(8.2)$ & $45.0(9.4)$ & $17.4(2.7)$ & 1204 & I 54.5 (5.8) & $44.1(8.6)$ & $18.4(3.1)$ \\
\hline 15 & 537 & I $64.3(7.4)$ & $49.3(10.0)$ & $18.2(2.9)$ & 648 & I55.2 (6.3) & $45.9(8.4)$ & $19.0(2.9)$ \\
\hline 16 & 211 & I66.I (6.7) & $52.7(10.7)$ & $19.0(3.2)$ & $13 \mid$ & I55.3 (6.4) & $46.2(8.4)$ & 19.1 (3.1) \\
\hline
\end{tabular}

Mean values of height, weight and body mass index. Figures in parenthesis are standard deviations.

Data of children in age group 15 years in $2003(n=6)$ and age group 6 years in $2005(n=2)$ are not shown in the table, as the number of children in the same is very low. 
Table 2: Age and gender specific mean BMI values according to socio demographic subgroups

\begin{tabular}{|c|c|c|c|c|c|c|c|c|}
\hline \multirow{2}{*}{$\begin{array}{l}2003 \\
\text { Age (yrs) }\end{array}$} & \multicolumn{4}{|c|}{ Boys } & \multicolumn{4}{|c|}{ Girls } \\
\hline & Urban & Rural & Govt & Private & Urban & Rural & Govt & Private \\
\hline 5 & I3.7 (I.2) & 13.9 (I.4) & I3.8 (I.3) & $14.2(1.4)$ & I3.7 (I.4) & I3.8 (I.5) & I3.8 (1.4) & I 4.5 (1.6) \\
\hline 6 & I4.5 (I.6) & 13.9 (1.5) & $13.9(1.4)$ & I5.0 (I.7) & $14.5(2.1)$ & $13.9(1.4)$ & $13.8(1.4)$ & $15.2(2.4)$ \\
\hline 7 & $14.6(2.1)$ & 13.9 (1.4) & 13.9 (I.5) & I5.3 (2.2) & I4.7 (2.0) & 13.9 (1.5) & 13.9 (I.5) & I5.I (2.1) \\
\hline 8 & I5.I (2.2) & I4.2(1.4) & |4.3 (I.4) & I5.5 (2.4) & I5.2(2.5) & 14.3 (I.7) & I4.3 (I.8) & $15.5(2.6)$ \\
\hline 9 & $15.6(2.6)$ & 14.5 (1.9) & 14.5 (1.9) & $16.3(2.7)$ & I5.5 (2.5) & $14.8(2.0)$ & $14.8(2.1)$ & $16.3(2.7)$ \\
\hline 10 & $15.8(2.9)$ & $14.6(2.1)$ & $14.7(2.1)$ & $16.9(3.2)$ & $15.6(2.5)$ & $15.0(2.1)$ & I5.I (2.2) & $16.8(2.7)$ \\
\hline II & $16.2(3.0)$ & $14.9(2.2)$ & $15.0(2.2)$ & $17.2(3.2)$ & $16.3(2.7)$ & $15.6(2.3)$ & $15.8(2.5)$ & I7.I (3.0) \\
\hline 12 & 16.I (2.7) & $15.5(2.2)$ & I $5.4(2.2)$ & $17.4(2.7)$ & $16.9(2.9)$ & $16.2(2.6)$ & $16.4(2.7)$ & $18.2(3.3)$ \\
\hline 13 & $17.2(3.3)$ & $15.8(2.0)$ & $16.0(2.4)$ & $18.2(3.6)$ & $17.5(2.7)$ & $16.8(2.5)$ & I7.I (2.6) & I8.2 (2.7) \\
\hline 14 & I7.I (3.3) & $16.8(2.5)$ & I 6.8 (2.7) & I8.4 (3.8) & I $7.8(2.7)$ & I $7.2(2.7)$ & I7.6 (2.7) & $18.4(2.8)$ \\
\hline \multicolumn{9}{|l|}{2005} \\
\hline 7 & I4.4 (2.0) & I4.0(I.5) & $13.9(1.4)$ & I5.6 (2.8) & $14.6(3.1)$ & $14.2(1.7)$ & I4.0 (I.6) & I6.I (4.2) \\
\hline 8 & $15.5(2.4)$ & 14.3 (1.9) & $14.5(2.0)$ & I6.I (2.6) & $15.0(2.3)$ & $14.5(1.8)$ & 14.4 (I.7) & I 5.8 (2.5) \\
\hline 9 & $15.8(2.5)$ & $14.5(2.0)$ & 14.6 (1.9) & $16.4(2.7)$ & $15.9(2.6)$ & $14.5(1.6)$ & $14.6(1.7)$ & $16.4(2.7)$ \\
\hline 10 & $16.3(2.8)$ & 14.8 (1.9) & I5.I (2.I) & $16.8(2.9)$ & $16.2(2.8)$ & $15.5(2.6)$ & $15.4(2.5)$ & $16.8(2.9)$ \\
\hline 11 & $16.8(2.9)$ & $15.6(2.5)$ & I $5.7(2.4)$ & $17.5(3.1)$ & $16.8(3.0)$ & I6.I (2.4) & $16.2(2.6)$ & I7.7 (3.2) \\
\hline 12 & $17.0(3.2)$ & $15.9(2.6)$ & $15.9(2.5)$ & $18.3(3.7)$ & $17.6(3.1)$ & $16.8(2.6)$ & $17.0(2.8)$ & $18.6(3.1)$ \\
\hline 13 & I7.5 (3.1) & $16.5(2.5)$ & I $6.6(2.6)$ & $18.4(3.3)$ & I8.| (2.9) & I $7.5(2.6)$ & I $7.8(2.7)$ & $18.7(2.9)$ \\
\hline 14 & I7.7 (2.9) & I $7.2(2.5)$ & I7.I (2.4) & $18.8(3.3)$ & $18.6(3.2)$ & $18.0(2.9)$ & $18.2(3.0)$ & $20.1(3.6)$ \\
\hline 15 & $18.5(3.3)$ & I7.7 (2.I) & I 7.7 (2.5) & $19.4(3.5)$ & $19.2(2.9)$ & I $8.5(2.7)$ & I8.8 (2.8) & $19.7(3.0)$ \\
\hline 16 & $19.3(3.6)$ & I8.7 (2.6) & I $8.7(2.8)$ & $20.7(4.2)$ & $19.2(2.9)$ & $19.0(3.6)$ & $19.0(3.1)$ & $20.3(2.6)$ \\
\hline
\end{tabular}

Figures in parenthesis are standard deviations

Govt- government schools

The anthropometric parameters (height, weight and BMI) were converted to their respective $Z$ scores based on reference population values [21] and analyzed (Table 4). The cohort showed significant improvements in height, weight and BMI during the study period as documented by corresponding increases in their mean $\mathrm{Z}$ scores $(\mathrm{P}<$ $0.001)$. Sub-group analysis of the cohort was done to look for the influence of socio demographic factors in this anthropometric transition. The rural subgroup showed significant improvements in weight and BMI Z scores $(\mathrm{P}<$ $0.001)$. The change in height $Z$ score was not significant. The urban sub group showed significant improvements in all three parameters $(\mathrm{P}<0.001)$. The government school subgroup showed significant improvements in weight and BMI Z scores $(\mathrm{P}<0.001)$ only where as private school group showed significant improvements in all three parameters $(\mathrm{P}<0.001)$. The boys sub group demonstrated an increase in all three parameters $(\mathrm{P}<0.001)$ where as girls demonstrated an increase in weight and BMI $Z$ scores only $(\mathrm{P}<0.001)$. In addition girls demonstrated a significant reduction in height $Z$ score $(P<0.01)$. The transitions of weight and BMI Z scores across various sub groups are presented as Figures 1 and 2 . The sub group based segregation of weight and BMI Z score distribution at the end of the study is presented as Figure 3.

The inter subgroup differences between the two time points were analyzed to look for any significant trends

Table 3: Weight transitions across weight groups (2003 to 2005)

\begin{tabular}{llllll}
\hline Weight status 2003 & Total & \multicolumn{3}{c}{ Weight status 2005 } \\
\hline & & UW & NW & OW & OB \\
UW & 4658 & $3035(65.2)$ & $1619(34.8)$ & $4(0.1)$ & 0 \\
NW & 6864 & $590(8.6)$ & $5963(86.9)$ & $284(4.1)$ & $27(0.4)$ \\
OW & 445 & 0 & $119(26.7)$ & $253(56.9)$ & $73(16.4)$ \\
OB & 162 & 0 & $10(6.2)$ & $41(25.3)$ & $111(68.5)$
\end{tabular}

Figures in parenthesis are percentages

UW -- Underweight, NW- Normal weight, OW- Overweight (excluding obese), OB- Obese 

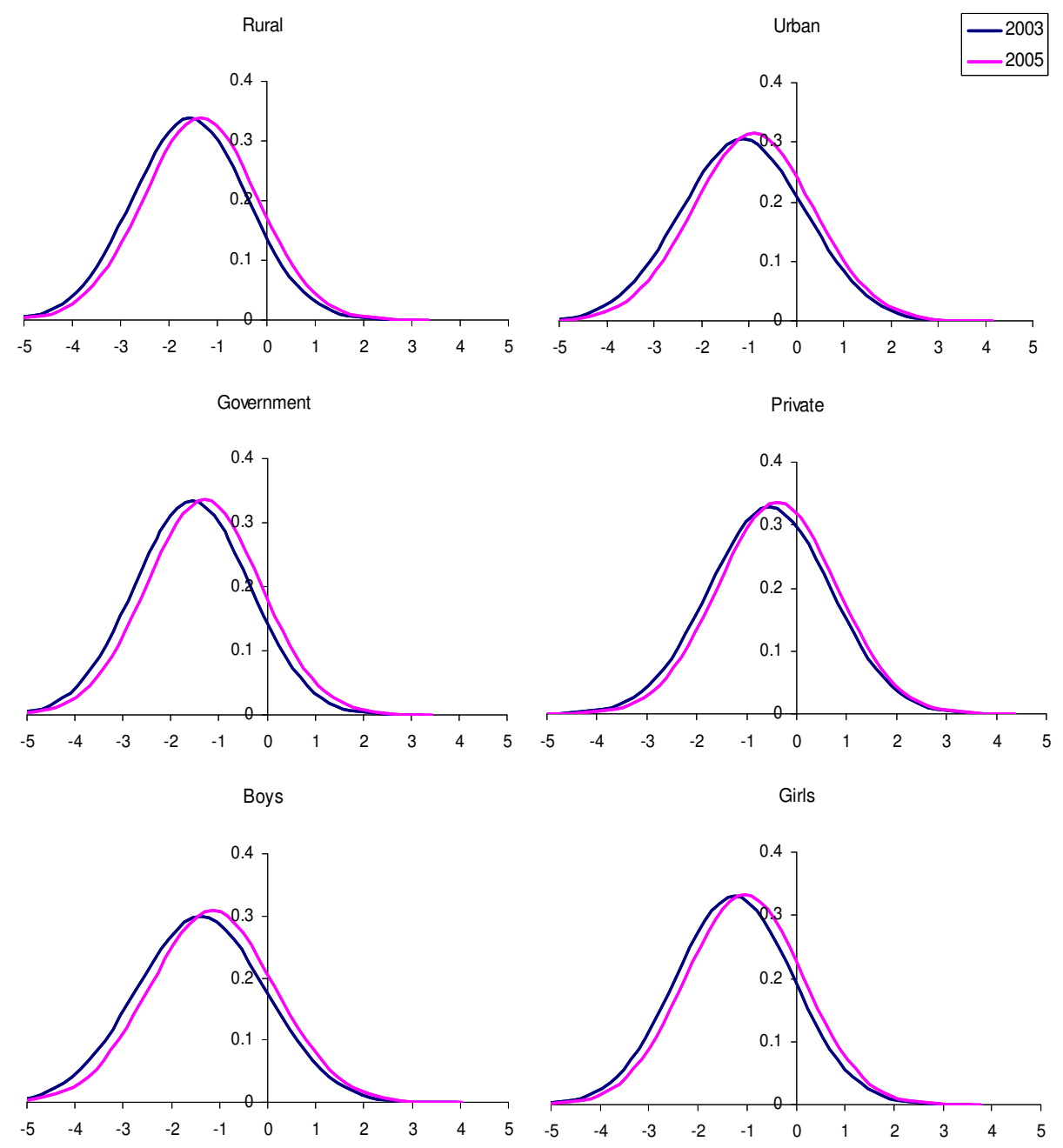

Figure I

Normal distribution curves for weight $\mathbf{Z}$ scores of subgroups. The curve labeled 2003 corresponds to distribution at the start of the study and the one labeled 2005 corresponds to distribution at the end of the study.

(Table 4). While the rural urban difference for height increased significantly during the study period $(\mathrm{P}<$ 0.001), the same for weight and BMI showed no significant changes. In terms of government private comparison, the difference in height increased significantly $(\mathrm{P}<$ $0.001)$, while that of weight $(P<0.001)$ and BMI decreased significantly $(\mathrm{P}<0.001)$. In comparing the gender subgroups, significant increase was found in height difference $(\mathrm{P}<0.001)$ where as weight difference showed a significant decrease $(\mathrm{P}<0.01)$. There was no significant change for difference in BMI.

For the sake of comparing demographic influences on the transition of weight status, overweight and obesity were grouped together to form the overweight group. The details are available in Table 5.

Among children who were underweight in the first survey, more from rural area remained underweight in the second survey than those from urban area $(67.5 \%$ Vs $62.7 \%$, P < $0.001)$. Among those who were underweight in the first survey, more children from urban area migrated to normal weight status in the second survey than from rural area $(37.2 \%$ Vs $32.4 \%, \mathrm{P}<0.001)$. The persistence of underweight during both surveys was more among boys compared to girls $(69.8 \% \mathrm{Vs} 59.4 \%, \mathrm{P}<0.001)$. The conversion of underweight status in the first survey to normal weight status in the second survey was seen more among girls than boys ( $40.5 \%$ Vs $30.1 \%, \mathrm{P}<0.001)$. 

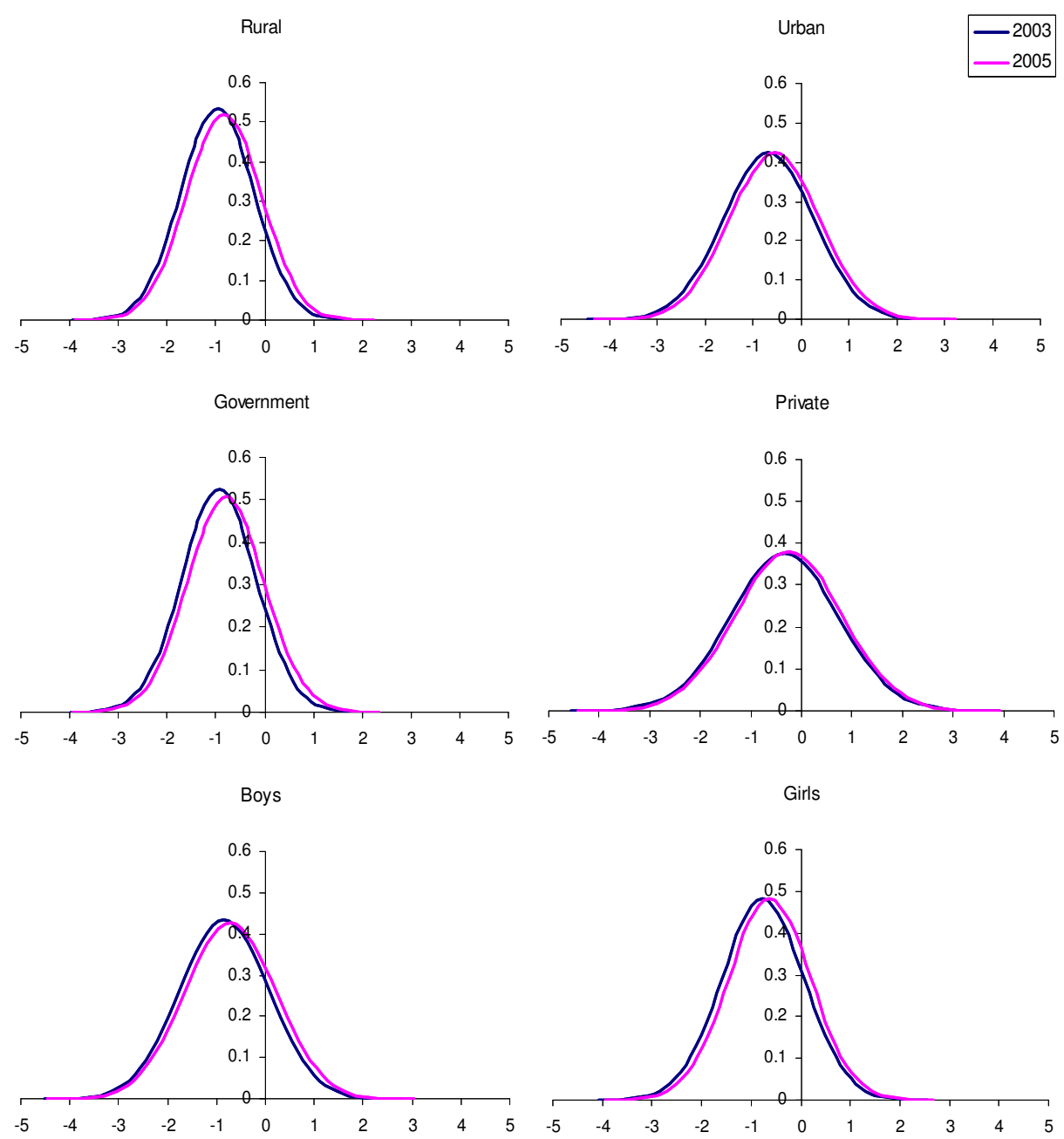

Figure 2

Normal distribution curves for BMI Z scores of subgroups. The curve labeled 2003 corresponds to distribution at the start of the study and the one labeled 2005 corresponds to distribution at the end of the study.

Among the normal weight children in the first survey, more from the rural area became underweight in the second survey compared to those from urban area $(10.1 \% \mathrm{Vs}$ 7.6\%, P $<0.001)$.

Of the children with normal weight status in the first survey, more children from government schools became underweight in the second survey compared to those from private schools $(9.3 \%$ Vs $6.7 \%, \mathrm{P}<0.001)$. Among the children with normal weight status in the first survey, more boys converted to under weight status in the second survey compared to girls $(11.3 \%$ Vs $6.6 \%, \mathrm{P}<0.001)$. Among the children with normal weight status in the first survey, more boys migrated to overweight status in the second survey compared to girls $(5.7 \%$ Vs $3.6 \%, \mathrm{P}<$ $0.001)$. Among the children with normal weight status in the first survey, more girls retained their normal weight status in the second survey when compared to boys (89.8\% Vs $83 \%, \mathrm{P}<0.001)$. No significant difference was seen between sub groups for transition of overweight status in the first survey to normal weight status in the second survey. Similarly no significant difference was noted between subgroups for persistence of overweight status in the two surveys.

\section{Discussion}

The dynamics of growth transition demonstrated by the cohort appears to be heterogeneous in nature. The positive shift in weight appears to be more when compared to that seen in height. A similar trend was reported by Vidal et al [22]. The rural as well as government school children have shown significant increments in weight and BMI Z scores but not in height $Z$ score. In contrast, both urban as well as private school children demonstrated significant 

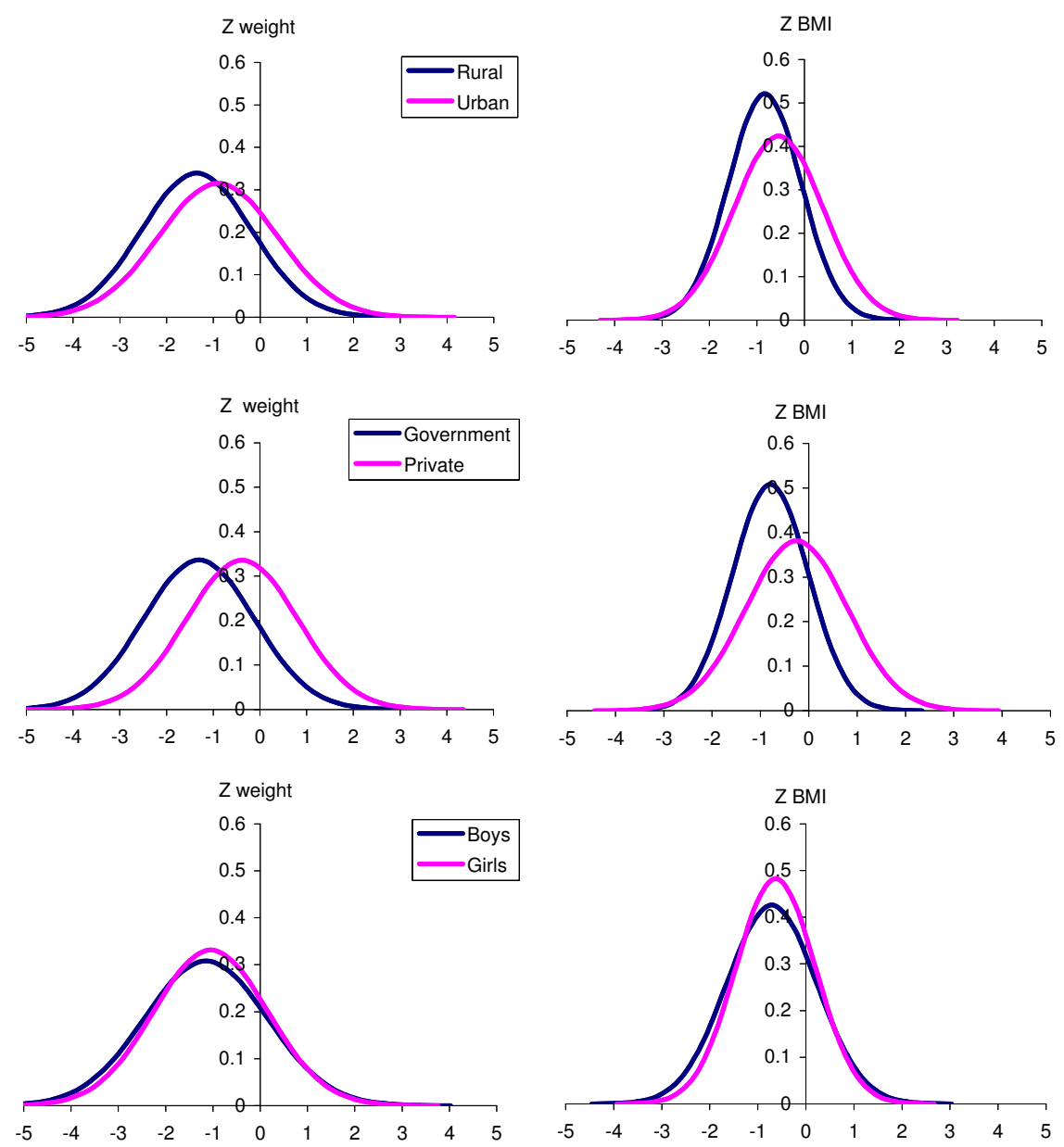

\section{Figure 3}

Comparison of final normal distribution curves of weight and BMI Z scores between subgroups. The normal distribution curves of weight and BMI Z scores were constructed from observations at the end of the study.

increases in height, weight and BMI Z scores. While the private and urban school children are becoming heavier and taller, the rural and government school children are simply becoming heavier and not taller. The findings also document that the time trend for linear growth remained stagnant in rural areas and low socioeconomic levels. It should be noticed that area of residence and type of school are acceptable surrogates of level of urbanization and socioeconomic status respectively in the Indian context. The government school children as well as the rural children are relatively poor. The private school children are relatively rich and the urban children are a mix of rich and poor. It is important to note that secular trends in height demonstrated during childhood could extend into adulthood [23]. This assumes significance due to the fact that adult height exhibits inverse linear associations with mortality from coronary heart disease and stroke as well as total mortality [24]. In addition, the study population exhibited relatively higher age, gender and height specific blood pressures suggesting that there is an increased cardiovascular risk visible even during childhood [25]. The combination of sub optimal adult height predictions with high blood pressures in childhood projects an adverse cardiovascular health profile in future for these children especially those belonging to low socio-economic levels.

All three sub group comparisons i.e. rural Vs urban, government Vs private as well as boys Vs girls demonstrated a significant widening of height difference. In terms of weight difference, significant decreases were seen in government Vs private as well as boys Vs girls comparisons. In terms of BMI difference, significant decrease was seen in government Vs private comparison. The study suggests that the socio economically advanced as well as the more urbanised segments of the pediatric population are growing relatively taller than their counterparts, promoting a 
Table 4: Trends in Z scores of Anthropometric parameters

\begin{tabular}{|c|c|c|c|c|c|c|c|c|c|c|}
\hline \multirow[t]{2}{*}{ Group } & \multirow[b]{2}{*}{$\mathbf{N}$} & \multicolumn{3}{|c|}{ Mean Z-height } & \multicolumn{3}{|c|}{ Mean Z-weight } & \multicolumn{3}{|c|}{ Mean Z-BMI } \\
\hline & & 2003 & 2005 & sig* & 2003 & 2005 & sig* & 2003 & 2005 & sig* \\
\hline All & 12129 & $-0.81(1.02)$ & $-0.79(0.99)$ & $<0.001$ & $-1.31(1.27)$ & $-1.09(1.25)$ & $<0.001$ & $-0.80(0.88)$ & $-0.67(0.88)$ & $<0.001$ \\
\hline Rural & 5240 & $-0.94(0.99)$ & $-0.94(0.95)$ & 0.823 & $-1.57(1.18)$ & $-1.36(1.18)$ & $<0.001$ & $-0.97(0.75)$ & $-0.83(0.77)$ & $<0.001$ \\
\hline Urban & 6889 & $-0.72(1.03)$ & $-0.68(1.01)$ & $<0.001$ & $-1.12(1.31)$ & $-0.90(1.26)$ & $<0.001$ & $-0.67(0.94)$ & $-0.54(0.94)$ & $<0.001$ \\
\hline sig** & & $<0.001$ & & & 0.416 & & & 0.887 & & \\
\hline Govt & 9358 & $-0.96(0.98)$ & $-0.96(0.94)$ & 0.488 & $-1.54(1.20)$ & $-1.31(1.19)$ & $<0.001$ & $-0.94(0.76)$ & $-0.79(0.78)$ & $<0.001$ \\
\hline Pvt & 2771 & $-0.31(0.96)$ & $-0.24(0.95)$ & $<0.001$ & $-0.54(1.22)$ & $-0.38(1.19)$ & $<0.001$ & $-0.33(1.06)$ & $-0.25(1.05)$ & $<0.001$ \\
\hline sig** & & $<0.001$ & & & $<0.001$ & & & $<0.001$ & & \\
\hline Boys & 5847 & $-0.79(1.02)$ & $-0.74(1.02)$ & $<0.001$ & $-1.38(1.34)$ & $-1.15(1.29)$ & $<0.001$ & $-0.84(0.92)$ & $-0.71(0.94)$ & $<0.001$ \\
\hline Girls & 6282 & $-0.83(1.01)$ & $-0.85(0.97)$ & $<0.008$ & $-1.25(1.21)$ & $-1.05(1.20)$ & $<0.001$ & $-0.76(0.83)$ & $-0.63(0.83)$ & $<0.001$ \\
\hline sig** & & $<0.001$ & & & 0.008 & & & 0.602 & & \\
\hline
\end{tabular}

Figures in parenthesis are standard deviations.

* Significance of paired sample test value

**Significance of independent sample test value

Govt- government schools, Pvt- private schools

progressive height divide in the population. The results also suggest that the weight divide between the higher and lower socio economic segments of the pediatric population is diminishing with time.

While boys have shown improvements in height, weight and BMI statuses, girls have shown improvements in weight and BMI statuses only. The gender divide in weight status is diminishing with time. Vidal et al reported a similar time trend of diminishing weight divide between the genders among children [22]. During the study period, boys showed an improvement in height status while girls showed a decline in the same as evidenced by their height $Z$ scores at the end of the study. The enhancement of gender divide in terms of height seen in the present study appears to be in contrast to the trend demonstrated by Vidal et al [22]. This disparity in growth pattern between the genders could probably be due to the combined effects of both physiological and socio demographic influences.

Table 5: Trends in weight status by socio demographic factors

\begin{tabular}{|c|c|c|c|c|c|c|c|c|}
\hline \multicolumn{5}{|c|}{2003 status } & \multicolumn{4}{|l|}{2005 status } \\
\hline & & Total & UW & $P$ value & Normal & P value & ow & $P$ value \\
\hline \multirow[t]{2}{*}{ UW } & Urban & 2289 & 1435 (62.7) & $<0.001$ & $852(37.2)$ & $<0.001$ & $2(0.1)$ & 0.67 \\
\hline & Rural & 2369 & $1600(67.5)$ & & 767 (32.4) & & $2(0.1)$ & \\
\hline \multirow[t]{2}{*}{ NW } & Urban & 4123 & $313(7.6)$ & $<0.001$ & $3595(87.2)$ & 0.335 & $215(5.2)$ & $<0.001$ \\
\hline & Rural & 2741 & $277(10.1)$ & & $2368(86.4)$ & & $96(3.5)$ & \\
\hline \multirow[t]{2}{*}{ ow } & Urban & 477 & 0 & - & $96(20.1)$ & 0.194 & 381 (79.9) & 0.194 \\
\hline & Rural & 130 & 0 & & $33(25.4)$ & & $97(74.6)$ & \\
\hline \multirow[t]{2}{*}{ UW } & Govt & 4078 & $2654(65.1)$ & 0.773 & $1420(34.8)$ & 0.809 & $4(0.1)$ & 0.587 \\
\hline & Private & 580 & $381(65.7)$ & & $199(34.3)$ & & $0(0.0)$ & \\
\hline \multirow[t]{2}{*}{ NW } & Govt & 5015 & $466(9.3)$ & $<0.001$ & 4357 (86.9) & 0.980 & $192(3.8)$ & $<0.001$ \\
\hline & Private & 1849 & $124(6.7)$ & & 1606 (86.9) & & $119(6.4)$ & \\
\hline \multirow[t]{2}{*}{ ow } & Govt & 265 & 0 & - & $65(24.5)$ & 0.082 & $200(75.5)$ & 0.082 \\
\hline & Private & 342 & 0 & & $64(18.7)$ & & $278(81.3)$ & \\
\hline \multirow[t]{2}{*}{ UW } & Boys & 2573 & I 797 (69.8) & $<0.001$ & $775(30.1)$ & $<0.001$ & I $(0.04)$ & 0.240 \\
\hline & Girls & 2085 & 1238 (59.4) & & $844(40.5)$ & & $3(0.1)^{\prime}$ & \\
\hline \multirow[t]{2}{*}{ NW } & Boys & 2945 & $332(11.3)$ & $<0.001$ & $2445(83.0)$ & $<0.001$ & $168(5.7)$ & $<0.001$ \\
\hline & Girls & 3919 & $258(6.6)$ & & $3518(89.8)$ & & 143 (3.6) & \\
\hline \multirow[t]{2}{*}{ ow } & Boys & 329 & 0 & - & $70(21.3)$ & 0.987 & 259 (78.7) & 0.987 \\
\hline & Girls & 278 & 0 & & $59(21.2)$ & & $219(78.8)$ & \\
\hline
\end{tabular}

Figures in parenthesis are percentages

UW -- Underweight

NW- Normal weight

OW- Overweight (inclusive of overweight and obesity)

Govt-Government schools 
It is evident that there is a shift in weight status as well as BMI status across all subgroups (Figures 1 \&2). A notable difference between the two transitions is that the shift in $\mathrm{BMI}$ in the private school children appears less impressive than other sub groups. This is despite the fact that private school children too had significant shifts in weight status like other sub groups. The reason for this disparity could be the fact that private school children are growing more symmetrically and the change in BMI is less due to significant gains in height status that accompanies their weight shift. Combining the above findings, it becomes clear that the low socio-economic segments of the pediatric population are experiencing overweight issues that are growing at a faster rate when compared to the same in higher socioeconomic segments. The asymmetry in the growth transition due to socio economic differences appears to be the major reason for this expansion of overweight population. The socio demographic segregation of weight and adiposity status distribution at the end of the study is expressed in Figure 3. The public health implications of this asymmetric, rapid growth transition in a population that already exhibits increased cardiovascular disease susceptibility could be serious.

The study indicates that the conversion of underweight to normal weight status occurs more in urban area and girls in comparison to rural area and boys respectively. The conversion of normal weight status to underweight status occurs more in rural area, government schools and boys when compared to their respective counterparts. The persistence of underweight appears to be significantly more with rural children and boys. These findings suggest that the favorable decline of underweight burden has socioeconomic and gender gradients.

During the study period (two years), the underweight population contracted by $22.2 \%$. In the same period, the overweight sub population has grown by $30.8 \%$ and the obese sub population by $30.3 \%$. A swift decline in the underweight population along with rapid growth of overweight and obese populations in the cohort suggests that the study population is going through an accelerated phase of nutritional transition. This transition is visible across the entire spectrum of weight distribution in the pediatric population.

The conversion of normal weight status to overweight status occurs more in urban areas, private schools, and boys in comparison to rural areas, government schools and girls respectively. In contrast, no significant influence of the same socio demographic factors was noticed in conversion of overweight population to normal weight status. In short, the beneficial conversion of overweight to normal weight appears to be due to other unidentified factors. The conversion of overweight to normal weight happening in the pediatric population could be due to multiple factors like individual awareness about overweight issues as well as attempts at the family, school, community, government or individual level to reduce the burden of overweight. The role of these factors as well as other unidentified ones need to be clearly identified for converting them into effective interventions aimed at reducing the burden of childhood obesity.

\section{Conclusion}

The pediatric population is experiencing a rapid growth and nutritional transition. A decline in the underweight population coupled with an escalation of overweight population is visible in the study. The low socio economic subsets of the pediatric population appear to grow in an asymmetric, unhealthy pattern. The heterogeneous nature of this transition appears to be due to differences in socioeconomic levels as well as varying grades of urbanisation.

\section{Competing interests}

The authors declare that they have no competing interests.

\section{Authors' contributions}

MR conceived, designed and drafted the study. KRS did the statistical analysis and contributed to the drafting of manuscript. MP managed the data and assisted in drafting the manuscript. AS assisted in statistical analysis and in data management. RKK supervised and revised the manuscript for important intellectual content. All authors read and approved the final manuscript. MR will act as guarantor of the study.

\section{Acknowledgements}

The study was fully supported by a grant from the Indian Council of Medical Research.

\section{References}

I. Darnton-Hill I, Coyne ET: Feast and famine: socioeconomic disparities in global nutrition and health. Public Health Nutr 1998, I:23-3I.

2. Amuna $\mathrm{P}$, Zotor $\mathrm{FB}$ : Epidemiological and nutrition transition in developing countries: impact on human health and development. Proc Nutr Soc 2008, 67:82-90.

3. Shetty PS: Nutrition transition in India. Public Health Nutr 2002, 5:175-182.

4. Zhai F, Wang H, Du S, He Y, Wang Z, Ge K, Popkin BM: Prospective study on nutrition transition in China. Nutr Rev 2009, 67(Suppl I):S56-6I.

5. Kosulwat $\mathrm{V}$ : The nutrition and health transition in Thailand. Public Health Nutr 2002, 5:183-189.

6. Lipoeto NI, Wattanapenpaiboon N, Malik A, Wahlqvist ML: Nutrition transition in west Sumatra, Indonesia. Asia Pac J Clin Nutr 2004, 1 3:312-316.

7. Lee SK, Sobal J: Socio-economic, dietary, activity, nutrition and body weight transitions in South Korea. Public Health Nutr 2003, 6:665-674.

8. Raj M, Sundaram KR, Paul M, Deepa AS, Kumar RK: Obesity in Indian children: time trends and relationship with hypertension. Natl Med J India 2007, 20:288-293.

9. Raj M: Obesity in Indian children - Time trends and implications. Indian J Pediatr 2009 in press. 
10. Wang Y: Cross-national comparison of childhood obesity: the epidemic and the relationship between obesity and socioeconomic status. Int J Epidemiol 2001, 3: I I29-1 I 36.

II. Ebbeling CB, Pawlak DB, Ludwig DS: Childhood obesity: publichealth crisis, common sense cure. Lancet 2002, 360:473-482.

12. James WPT, Nelson M, Ralph A, Leather S: Socioeconomic determinants of health: the contribution of nutrition to inequalities in health. $B M J 1997,314: 1545-1549$.

13. Gordon-Larsen P, McMurray RG, Popkin BM: Determinants of adolescent physical activity and inactivity patterns. Pediatr 2000, 105:I-8.

14. Doak C, Adair L, Bentley M, Fengying Z, Popkin B: The underweight/overweight household: an exploration of household sociodemographic and dietary factors in China. Public Health Nutr 2002, 5:215-221.

15. Popkin BM: An overview on the nutrition transition and its health implications: the Bellagio meeting. Public Health Nutr 2002, 5(suppl):93-103.

16. Dunton GF, Kaplan J, Wolch J, Jerrett M, Reynolds KD: Physical environmental correlates of childhood obesity: a systematic review. Obes $\operatorname{Rev} 2009$, 10:393-402.

17. Matijasevich A, Victora CG, Golding J, Barros FC, Menezes AM, Araujo CL, Smith GD: Socioeconomic position and overweight among adolescents: data from birth cohort studies in Brazil and the UK. BMC Public Health 2009, 9:105.

18. Ji CY, Sun JL, Chen TJ: Dynamic analysis on the prevalence of obesity and overweight school-age children and adolescents in recent 15 years in China. Zhonghua Liu Xing Bing Xue Za Zhi 2004, 25: 103-108.

19. Kaur S, Sachdev HP, Dwivedi SN, Lakshmy R, Kapil U: Prevalence of overweight and obesity amongst school children in Delhi, India. Asia Pac J Clin Nutr 2008, 17:592-596.

20. Barlow SE, Dietz WH: Obesity evaluation and treatment: Expert Committee recommendations: The Maternal and Child Health Bureau, Health Resources and Services Administration and the Department of Health and Human Services. Pediatrics 1998, 102:E29 [http://pediatrics.aappublications.org/ cgi/reprint/l02/3/e29].

21. Department of Health and Human Services, Centers for Disease control and Prevention, USA: CDC growth charts for the United States. percentile data files.htm]

22. Marques-Vidal P, Madeleine G, Romain S, Gabriel A, Bovet P: Secular trends in height and weight among children and adolescents of the Seychelles, 1956-2006. BMC Public Health 2008, 8:166.

23. Cole TJ: The secular trend in human physical growth: a biological view. Econ Hum Biol 2003, I:161-168.

24. Lee CM, Barzi F, Woodward M, Batty GD, Giles GG, Wong JW, Jamrozik K, Lam TH, Ueshima H, Kim HC, Gu DF, Schooling M, Huxley RR, for The Asia Pacific Cohort Studies Collaboration: Adult height and the risks of cardiovascular disease and major causes of death in the Asia-Pacific region: 21 000 deaths in 510000 men and women. Int J Epidemiol 2009, 38:1060-107I.

25. Raj M, Sundaram KR, Paul M, Kumar RK: Blood pressure distribution in children. Indian Pediatr 2009 in press. http://indianpediat rics.net/RP030909/RP-123.pdf pii: S097475590800 I23-I.
Publish with Bio Med Central and every scientist can read your work free of charge

"BioMed Central will be the most significant development for disseminating the results of biomedical research in our lifetime. "

Sir Paul Nurse, Cancer Research UK

Your research papers will be:

- available free of charge to the entire biomedical community

- peer reviewed and published immediately upon acceptance

- cited in PubMed and archived on PubMed Central

- yours - you keep the copyright

Submit your manuscript here:

http://www.biomedcentral.com/info/publishing_adv.asp
BioMedcentral 